\title{
Study on the Relationship between Strength and Water-Cement Ratio for the EPS Silt Light-Weight Soil Based on Gray Verhulst Model
}

\author{
Yong Feng*
}

School of Civil Engineering, Henan University of Technology, Zhengzhou, Henan, 450001, China

\begin{abstract}
PS silt mixed soil is a high quality synthetic fill material made of foam material and sludge wasted. This paper indicates according to the test results and the previous studies that: the intensity of light-weight soils is increasing as the grey water ratio increases, and when the gray water ratio reaches a certain value, the strength of the growth rate is not large. Therefore, the research of the relationship of its strength and water-cement ratio for providing accurate design parameters of soil particles lightweight soil is very important. According to existing research results, a number of samples were made to study the relationship between strength and water-cement ratio, then the analyzed curves were obtained. In this paper, based on the gray Verhulst model, the variation regulation between the strength and water ratio was fitted. The study showed that the fitted curve was similar with the measured curve. It is found that the measured curves can be derived from fitted curve available, the related research can give good references for construction of EPS silt light-weight soil.
\end{abstract}

Keywords: EPS silt light-weight soil, fitted curve, gray verhulst model, strength, water-cement ratio.

\section{INTRODUCTION}

EPS silt soil mix lightweight soil technology treats sludge as a "resource" from a new perspective, by adding wasted polystyrene foam (Expanded polystyrene sheet, referred to as EPS), curing agent, mixed together into a certain mixed strength light weighted synthetic filler [1,2]. Thus EPS lightweight silt soil is a new type of geotextile material, harmless, not producing soil pollution problems due to its stable physical properties. But the technology can be the foam material waste and sludge into high-quality filling materials, which make waste recycling is one of the emerging environmental geotechnical engineering and development of the main research directions [3].

For this new filling soil material, its compressive strength is the most important mechanics quality $[2,4]$. The material mechanics performance test by more than 20 department in Japan showed that the relationship between stress and strain of this material belonged to the cementation type. The compression test made by Japan's researcher in 1996 showed the yield stress was closely related with uniaxial compressive strength [5]. Kamaluddin.M studied the consolidation properties of this light-weight material, which found that the consolidation of this material was similar to the overconsolidated soil. Helene Tremblay studied the compression feature by compression test, but the compression feature of the EPS was not accounted.

The obvious feature of the EPS silt lightweight soil material is the high strength [6], besides, the strength can be adjusted within a certain range by changing the content of lightweight material, which is also one of the main factors for this lightweight soil materials use as the filling soil. For all the affecting factors of the strength, the most important factor is the water-cement ratio.

Reasonable access to high-precision physics, mechanics parameters are always research priorities in geotechnical engineering, in which its strength characteristics is the most concerned [6, 7]. The present research shows: the strength of light weight soil increases with gray water ratio increasing, and when the ratio of the gray water reaches a certain value, the strength of the growth rate is not obvious. Therefore, the research of the relationship between water-cement ratio and its strength is important for providing accurate design parameters of particles lightweight soil.

\section{EXPERIMENTAL PROCEDURE AND RESULT ANALYSIS}

\subsection{The Preparation of Samples}

For the raw materials of this new lightweight soil, the silt of yellow river beach was chose (the natural moisture content is from $51.6 \%$ to $78.7 \%$, the natural unit weight is from $15.23 \mathrm{kN} / \mathrm{m} 3$ to $17.17 \mathrm{kN} / \mathrm{m} 3$, the saturation degree is from $92 \%$ to $100 \%$, the natural void ratio is from 1.11 to 2.28 ). The EPS particles were made by pulverizing foam packaging materials, they were globular particles and the size of them is from 1 to 3 millimeters. The curing agent used the composite Portland cement number 32.5 (China) which contains little slag and the live use water was also chose in madding the test sample. A three disc (the diameter is $3.91 \mathrm{~cm}$ high and the height is $8 \mathrm{~cm}$ ) was designed for the density test.

\subsection{Test Method for the Compressive Strength}

Unconfined compressive strength is the ultimate axial strength with no lateral pressure resistance. In this study, the test for the unconfined compressive strength chose the STLQ 
- 3 type display material strength tester as the test equipment, the process of the test was controlled by strain. In order to obtain the mixing ratio with good feature and small density, the changing rule for the compressive strength with the water-cement ratio was studied.

\subsection{Test Results Analysis}

According to related test procedures, at first, taking the axial stress as the ordinate and axial strain as the abscissa, then the stress - strain curve was obtained. Based on these curves, the maximum axial stress should be selected as the unconfined compressive strength. If the maximum axial stress is not obvious, the stress at $15 \%$ axial strain should be chose as the compressive strength. Based on the datas. then the analyzed curves were obtained.

\section{GRAY VERHULST MODEL}

\subsection{Characteristic of Grey Verhulst Predictive Model}

Based on Verhulst theory, gray Verhulst predictive model is formed by using the advantages of gray system modeling information needed and small samples and by using the specific method. It is "S" shaped curve to describe a system tending to saturation state, as it is shown in the following Fig. (1).

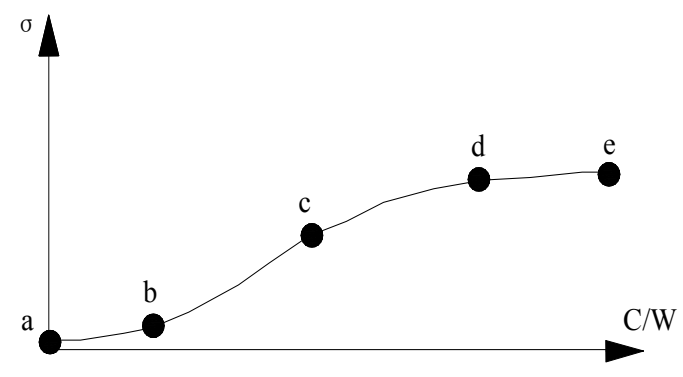

Fig. (1). Gray verhulst model.

\subsection{Grey Verhulst Predictive Model}

Record of the original intensity measured data sequence:

$\sigma^{(1)}=\left\{\sigma^{(1)}(1) \sigma^{(1)}(2) \ldots \mid \sigma^{(1)}(n)\right\}$

Record of the original settlement's corresponding time sequence:

$\left(\frac{C}{W}\right)^{(1)}=\left\{\left(\frac{C}{W}\right)^{(1)}(1)\left(\frac{C}{W}\right)^{(1)}(2) \ldots \mid\left(\frac{C}{W}\right)^{(1)}(n)\right\}$

Record of a regressive generation sequence:

$\sigma^{(0)}=\left\{\sigma^{(0)}(1) \sigma^{(0)}(2) \ldots \mid \sigma^{(0)}(n)\right\}$

$\left(\frac{C}{W}\right)^{(0)}=\left\{\left(\frac{C}{W}\right)^{(0)}(1)\left(\frac{C}{W}\right)^{(0)}(2) \ldots \mid\left(\frac{C}{W}\right)^{(0)}(n)\right\}$

According to the gray system modeling method, you can get first-order nonlinear dynamic differential equations, which is verhulst model. $\frac{d \sigma^{(1)}}{d(C / W)}+a \sigma^{(1)}=b\left(\sigma^{(1)}\right)^{2}$

In the formula: $\mathrm{a}$ is developmental quotient; $\mathrm{b}$ is gray actuating quantity; $\mathrm{a}, \mathrm{b}$ value can be estimated by least squares.

$\left\{\begin{array}{l}a \\ b\end{array}\right\}=\left(B^{T} B\right)^{-1} B^{T} Y$

In which:

$B=\left[\begin{array}{cccc}\left(\frac{C}{W}\right)^{(0)}(2) & 0 & \ldots & 0 \\ 0 & \left(\frac{C}{W}\right)^{(0)}(3) & \ldots & 0 \\ \ldots & \cdots & \ldots & \ldots \\ 0 & 0 & \ldots & \left(\frac{C}{W}\right)^{(0)}(n)\end{array}\right]\left[\begin{array}{c}-Z^{(1)}(2)\left(Z^{(1)}(2)\right)^{2} \\ -Z^{(1)}(3)\left(Z^{(1)}(3)\right)^{2} \\ \ldots \\ -Z^{(1)}(n)\left(Z^{(1)}(n)\right)^{2}\end{array}\right]$

$Y=\left[\begin{array}{c}\sigma^{(0)}(2) \\ \sigma^{(0)}(3) \\ \ldots \\ \sigma^{(0)}(4)\end{array}\right]$

$Z^{(1)}(i)=\frac{1}{2}\left[\sigma^{(1)}(i-1)+\sigma^{(1)}(i)\right], i=2,3, \ldots, n$

The result of the differential equation is:

$$
\sigma^{(1)}(t)=\frac{a \sigma^{(1)}(t)}{b \sigma^{(1)}(t)+\left(a-b \sigma^{(1)}(t)\right)_{e}^{a \frac{C}{W}}}
$$

Time formula of gray model Verhulst is obtained by discrete formula (9):

$\hat{\sigma}^{(1)}(k+1)=\frac{a \sigma^{(1)}(1)}{b o^{(1)}(1)+\left(a-b o^{(1)}(1)\right)_{e}^{a\left\{\left(\frac{c}{w} w^{(1)}(k+1)-\left(\frac{c}{w}\right)^{(1)}(1)\right\}\right.}}$

Known by the formula (10) above, the corresponding settlement $\mathrm{S}$ can be solved by time $\mathrm{t}$.

\subsection{Detection of Model's Precision}

A model's correctness and rationality can be tested by the quality of the model. Grey Verhulst predictive model in this paper takes method of gray forecasting model with residual:

When accuracy of gray model verhulst does not meet the requirements, the model can be amended by building residuals verhulst prediction model by using available residual series to improve the accuracy. After superimposing, the following equation (11) can be worked out.

$$
\hat{\sigma}^{(1)}(k+1)=\frac{a \sigma^{(1)}(1)}{b o^{(1)}(1)+\left(a-b o^{(1)}(1)\right)_{e}^{a\left\{f^{(1)}(k+1)-t^{(1)}(1)\right\}_{e}^{3}}}+\alpha \cdot e^{-\left(\frac{w c^{-\beta}}{r}\right)^{2}}
$$

Accuracy of the settlement prediction value obtained by formula (11) can be further tested. If it cannot meet the requirements, then the residual can be corrected until it can meet the requirements of accuracy. 
Table 1. Parameters of curve fitting under different EPS content.

\begin{tabular}{|c|c|c|c|c|c|c|}
\hline Fitting parameters & $\begin{array}{c}\text { EPS } \\
(0.66 \%)\end{array}$ & $\begin{array}{c}\text { EPS } \\
(1.33 \%)\end{array}$ & $\begin{array}{c}\text { EPS } \\
(2.00 \%)\end{array}$ & $\begin{array}{c}\text { EPS } \\
(2.67 \%)\end{array}$ & $\begin{array}{c}\text { EPS } \\
(\mathbf{3 . 3 3} \%)\end{array}$ & $\begin{array}{c}\text { EPS } \\
(4.00 \%)\end{array}$ \\
\hline$a_{i}$ & -0.4462 & 0.3911 & -0.3749 & -0.3067 & -0.2580 & -0.2126 \\
\hline$b_{i}$ & -0.00026 & -0.00032 & -0.00040 & -0.00041 & -0.00048 & -0.00050 \\
\hline$\alpha \mathrm{i}$ & 331 & 208 & 154 & 53 & 16 & 12 \\
\hline$\beta \mathrm{i}$ & 10.0 & 9.5 & 10 & 10.6 & 12.5 & 0.48 \\
\hline$\gamma \mathrm{i}$ & 2.04 & 2.59 & 2.16 & 1.5 & 1.78 & 0.16 \\
\hline
\end{tabular}

\section{FITTING FORMULA FOR THE LIGHTWEIGHT SOIL STRENGTH CHANGING WITH THE WATER- CEMENT RATIO}

According to the above analysis, changes of the intensity of lightweight soil going with the amount of soil was "S"type, so the fitting curve can be simulated by the following formula (12) and the specific fitting parameters can be shown in Table 1. As can be seen from the table, regardless of the changes in EPS, the slope of the fitted curve is small, and what affects decisively lightweight soil strength is the intercept. Therefore, the impact of gray water ratio on the strength is not large, and EPS content has a great impact on density of lightweight soil. Fig. (2) shows the relationship curve after fitting.

$$
\hat{\sigma}^{(1)}(k+1)=\frac{a \sigma^{(1)}(1)}{b o^{(1)}(1)+\left(a-b o^{(1)}(1)\right)_{e}^{a\left\{\frac{(c)(1)}{w}(k+1)-\left(\frac{c}{w}\right)^{(1)}(1)\right\}}}+\alpha \cdot e^{-\left(\frac{w / c^{-\beta}}{r}\right)^{2}}
$$

In the formula: $\sigma$ is the intensity of lightweight soil; $\frac{C}{W}$

is gray water ratio of lightweight soil; $a_{i}, b_{i}, \alpha_{i}, \beta_{i}, \gamma_{i}$ is parameters of curve fitting under different EPS dosage.

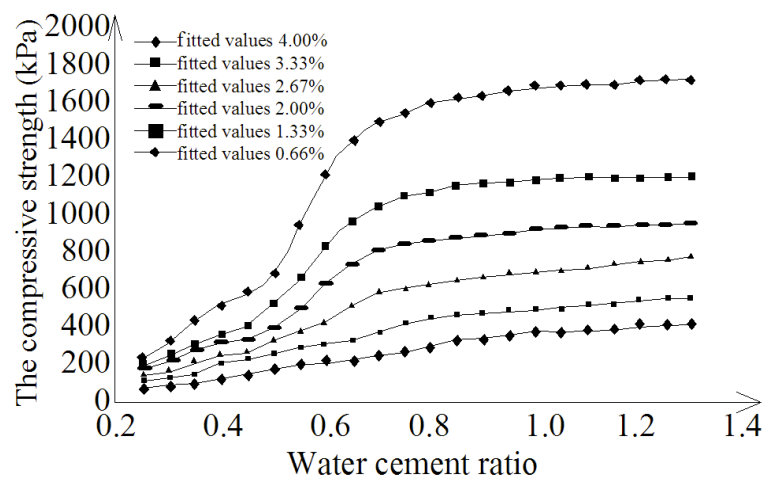

Fig. (2). Curve fitting picture of lightweight soil strength under different EPS content.

\section{THE FITTED CURVE AND ERROR ANALYSIS FOR THE RELATIONSHIP BETWEEN STRENGTH AND WATER-CEMENT RATIO UNDER DIFFERENT EPS CONTENT}

Based on the study of influencing factors for the EPS silt mixed lightweight soil material, it was found that the incorporation of the EPS and cement were the main influencing factors of compressive strength. The effect of the cement content on the compressive strength of this light-weight soil is related with the EPS content. When the EPS content is smaller, the effect of the cement content on the compressive strength is larger, the cement content is the main factor for the strength. But when the EPS content exceeds a critical value, the effect of cement increment on the strength becomes smaller. So it is necessary to study the relationship between strength and water-cement ratio under different EPS content.

A number of groups under different EPS content were researched in the experiment, the typical results are showing in the following Figs. (3-5). It is showed that the changes of intensity of lightweight soil going with gray water are nonlinear change. According to the test results, the intensity of lightweight soil can be fitted using gray Verhulst model. As is shown in the picture, the contrast of fitting curve to the measured values shows that fitting curve fits better with the measured values, so using fitting curve instead of using the measured curve is feasible.

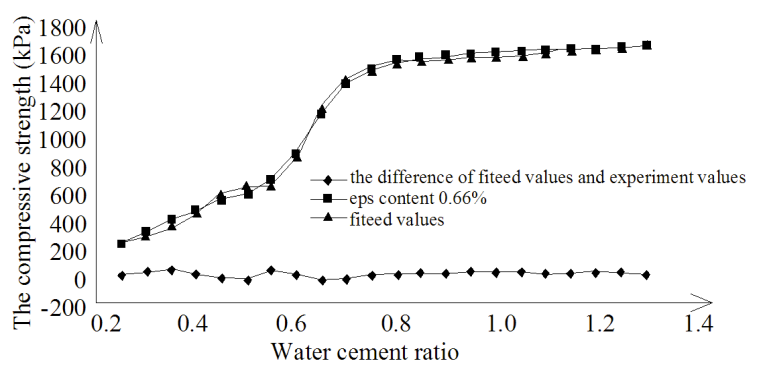

Fig. (3). The change regulation and fitting curve of lightweight soil intensity going with gray water.

(ESP Takes $0.66 \%$ )

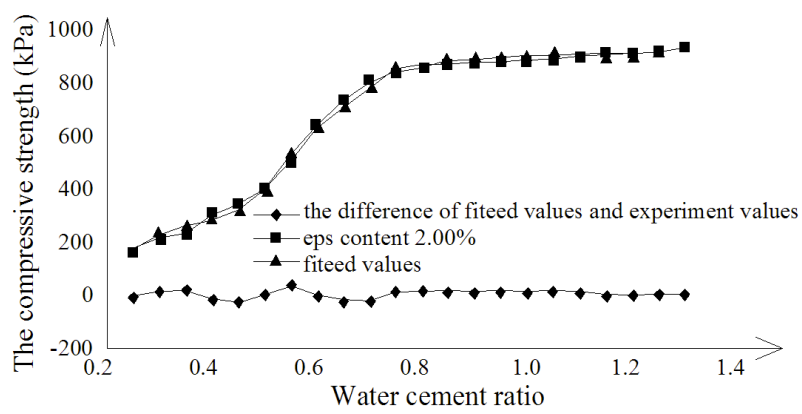

Fig. (4). The change regulation and fitting curve of lightweight soil intensity going with gray water. 
Table 2. Relevant parameter of fitting curves under different eps content.

\begin{tabular}{|c|c|c|c|c|c|c|}
\hline & $\begin{array}{c}\text { EPS } \\
(0.66 \%)\end{array}$ & $\begin{array}{c}\text { EPS } \\
(1.33 \%)\end{array}$ & $\begin{array}{c}\text { EPS } \\
(2.00 \%)\end{array}$ & $\begin{array}{c}\text { EPS } \\
(2.67 \%)\end{array}$ & $\begin{array}{c}\text { EPS } \\
(3.33 \%)\end{array}$ & $\begin{array}{c}\text { EPS } \\
(4.00 \%)\end{array}$ \\
\hline Pertinence & 0.986 & 0.983 & 0.968 & 0.994 & 0.956 & 0.947 \\
\hline The goodness-of-fit statistics & 0.967 & 0.996 & 0.947 & 0.998 & 0.935 & 0.932 \\
\hline The maximum of difference between the fitting values & 54.1 & 37.2 & 39.3 & 8.6 & 16.4 & 17.3 \\
\hline
\end{tabular}

(ESP Takes 2.00\%)

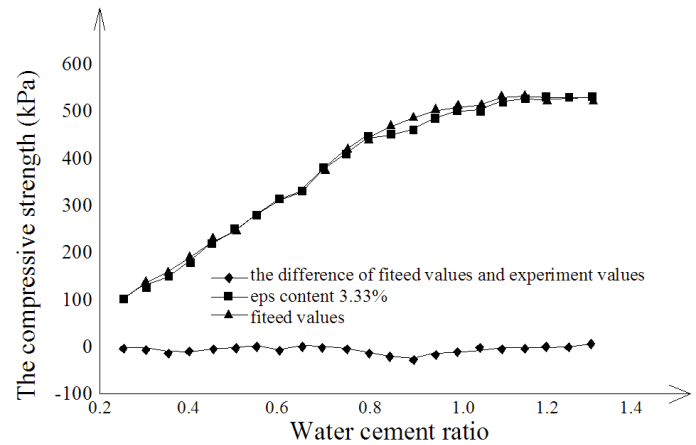

Fig. (5). The change regulation and fitting curve of lightweight soil intensity going with gray water.

\section{(ESP Takes 3.33\%)}

The following Table $\mathbf{2}$ is relevant parameter of fitting curves under different EPS dosage, which shows that the measured curve and fitting curve have a good correlation. The fitting degree is relatively high, and the difference between the maximum value and the measured value is small, so fitting curve is credible. Fig. (6) shows the relation of measured lightweight soil strength curve and fitting curve under different EPS content. The study showed that the fitted curve was similar with the measured curve. It is found that the measured curves can be derived from fitted curve available, the related research can give good references for construction of EPS silt light-weight soil.

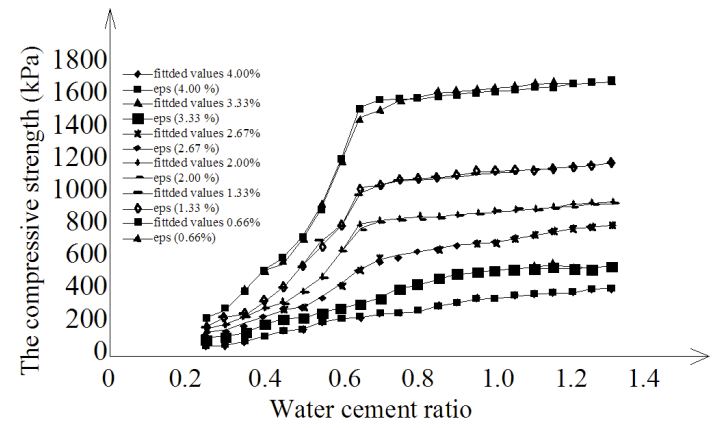

Fig. (6). Contrast diagram of measured lightweight soil intensity curve and fitting curve.

\section{CONCLUSION}

The changes of intensity of lightweight soil going with gray water are non-linear changes. According to the test results, the intensity of lightweight soil can be fitted by gray Verhulst model. The contrast of fitting curve to the measured values shows that fitting curve fits better with the measured values, so using fitting curve instead of using the measured curve is feasible.

\section{CONFLICT OF INTEREST}

The author confirms that this article content has no conflict of interest.

\section{ACKNOWLEDGEMENTS}

This work was financially supported by the 2013 Zhengzhou city science and technology plan projects "EPS silt renewable hybrid lightweight soil technology and application" (20130820) and Zhengzhou city science and technology plan projects (academician workstation construction plan) (project number: 131 pysgz205) funding.

\section{REFERENCES}

[1] Y. Zhu, "Experimental study on the polystyrene lightweight mixed soil infiltration characteristics," Hohai University Master's degree thesis, Nanjing, 2006.

[2] T. Hou, and G. Xu, "Foam particle mixing lightweight soil shear strength characteristics of experimental research," Journal of China University of Mining, vol. 39, no. 4, pp. 534-540, 2010.

[3] Y. Feng, Y. Li, and J. Lou, "Lightweight soil technology and its application in highway engineering disease prevention and control of disasters," Engineering Investigation, no. 10, pp. 38-42, 2006.

[4] Y. Li, T. Wu, and F. Yong, "EPS technology and its application in road construction of the roadbed and bridge abutment," Geotechnical Engineering Technique, vol. 19, no. 6, pp. 311-314, 2005.

[5] J. Jian, Z. Ming, and H. Yu, "Unconfined compressive strength and the ratio of lightweight soil parameters of nonlinear regression analysis," Journal of Zhejiang Water Conservancy and Hydropower College, vol. 19, no. 4, pp. 5-7, 2007.

[6] L. Sha, S. Du, and Z. Luo, "The elastic wave velocity of EPS lightweight soil ultrasonic test research," Subgrade Engineering, pp. 3233, 2008.

[7] Zhejiang, College of Construction. "Lightweight soil new technology application in the bridge foundation in soft soil area of research", Zhejiang province department of key research projects, 2007. 